\title{
Modelling and Stability Analysis for a Variable Speed DC Tidal/Wind Turbines with MPPT in Low Voltage DC Microgrid
}

\author{
Walid Nassar \\ Electronic a nd El ectrical depratment \\ Unive rsity of Strathclyde \\ Glasgow, UK \\ walid-mohmady-hassan-nassar@strath.ac.uk
}

\author{
Olimpo Anaya -Lara \\ Electronic a nd El ectrical depratment \\ Unive rsity of Strathclyde \\ Glasgow, UK \\ olimpo.anaya-lara@strath.ac.uk
}

\begin{abstract}
DC Microgrid is a new candidate for Multi-Purpose Platforms (MPP) which highly supported by the international community for sustainably exploiting our oceans. Considering DC-systems for the MPP requires all renewable energy sources to be interfaced to a DC-bus. Wind turbines as proven developed energy for offshore use is a crucial energy source for MPP. Normally, a wind turbine in a DC-environment uses a diode rectifier for interfacing to the grid and a DC-DC boost or buck converter for extracting maximum power. Previous studies included wind turbine in a DC-microgrid did not analyze the turbine stability with wind variations. Moreover, tidal turbines, as an immature technology, are rarely considered in such DCsystems. So, this paper provides a modelling and stability analysis for a wind/tidal turbines based Permanent Magnet Synchronous Generator (PMSG). A linearized small-signal model is derived for a wind/tidal turbines based PMSG and boost converter. Two control loops are used for speed and current control. Stability analysis shows that the controller can effectively keep the system stable under wind/tidal speed variations. Simulation analysis is carried out to shows the effectiveness of the controller at various speeds considering tidal and wind turbines.
\end{abstract}

Index Terms-Boost converter, wind turbine, DC microgrid, tidal turbine, modelling, stability analysis, MPPT

\section{INTRODUCTION}

$\mathrm{T}_{\mathrm{s}}$ HE international efforts to exploit oceans sustainably are supported by two big European funded projects, the Ocean of Tomorrow and Horizon 2020. There are many configurations and structures of marine energy units which are exploited at Multi-Purpose Platforms (MPP) [1]. Presenting energy unit based DC-system is a new candidate which never been studied for such platforms. This requires all Renewable Energy Sources (RES) to be interfaced to the DC-bus via DC-DC converters which already presented in previous studies.

Study [2] proposed a two-loop control scheme to maintain the DC voltage fixed within a DC microgrid. One of the components of this microgrid is a wind turbine which is controlled using a DC-DC boost converter for MPPT. Zammit et. al. [3] presented an MPPT strategy for a small wind turbine based on the DC-link power and voltage without the need for wind or speed measurements. The turbine is connected to the DC bus via a diode rectifier and a boost converter. Boost converter inductor current is controlled to maintain the DC-link fixed according to the maximum power available. Study [4] proposed a supervisory controller with adaptive droop control to control an autonomous DC microgrid, which includes several distributed generators (wind and solar PV) with a pair of batteries. The full-scale wind turbine is controlled for MPPT using a buck converter. Study [5] proposed a coordinated control strategy based on bus signaling method to avoid overcharging and discharging of the battery system in a LVDC islanded microgrid. RES are considered with a DC-DC converter for three operation modes: MPPT mode at SOC lower than its maximum level, voltage support mode at maximu $\mathrm{m}$ SOC and idle mode at maximu $\mathrm{m}$ SOC and lower load demand required. Study [6] proposed a voltage droop control strategy based power-sharing and coordination strategy among slack terminals (grid and energy storage system) for grid-connected and autonomous modes. A wind turbine included in this microgrid is interfaced to the DC bus via diode rectifier and DC-DC converter. Similarly, studies [7-10] interfaced the wind turbine to a DC microgrid via rectification stage and DC-DC converters. None of the above-mentioned studies analyzed the DC turbine stability with wind speed variations. So, this paper presents a modelling and stability analysis of a DC wind/tidal turbines based PMSG considering the common systemstructure in those studies. Only one operation mode is considered for the turbine under this paper which is MPPT mode. In other words, pitch control is not considered neither voltage support mode because the main focus of this study is to analyze the turbine stability with wind speed variation which is not considered in any of the previously-mentioned studies.

The rest of the paper is organized as follow: system configuration introduced in section II, the mathematical model of a wind/tidal turbine with PMSG and boost converter is derived in section III. Then, stability analysis of the transfer function between wind speed and boost converter inductor current and the system simulation are explored in sections IV and $\mathrm{V}$, respectively. The paper is concluded in section VI.

\section{SYSTEM CONFIGURATION}

DC wind or tidal turbines could be an elements of a DC microgrid such as the one shown in Fig. 1. The turbines are connected to the DC bus via diode rectifier and boost converter for extracting the maximum power. 


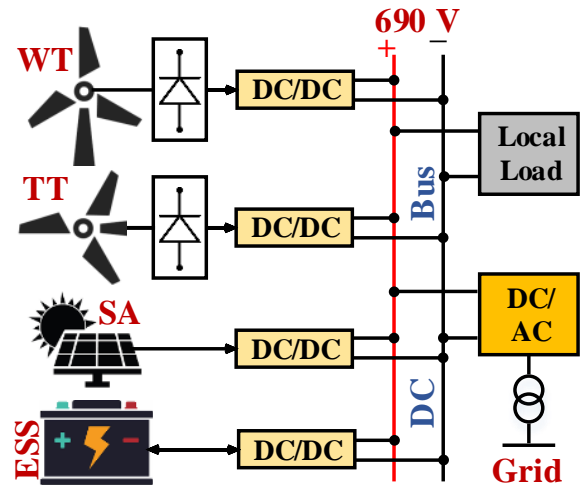

Fig. 1 Part of a DC microgrid (grid connected or islanded) includes wind turbine, tidal turbine, solar array and energy st orage.

\section{MODELLINGOF WIND/ TIDAL TURBINE WITHMPPT CONTROLLER}

As illustrated in Fig. 1, each wind or tidal turbine is connected to a Permeant Magnet Synchronous Generator (PMSG), Diode Bridge and DC/DC boost converter. Due to its widespread acceptance in wind turbines applications and its fast progress, (PMSG) is considered under this study to be connected to the wind and tidal turbines [11]. Boost converter is used to extract the maximum power from the wind turbine via two control loops. The first loop tracks the optimal generator speed using Proportional Integral (PI) which provides a reference for inductor current of the second current loop. The second loop, also, uses PI to control the inductor current which leads to controlling the speed of the generator to operate at the optimal speeds. Fig. 2 shows the block diagram for speed control of PMSG connected to wind/tidal turbine. The following model applies to wind/tidal turbine as similar configuration is considered for both of them under this study.

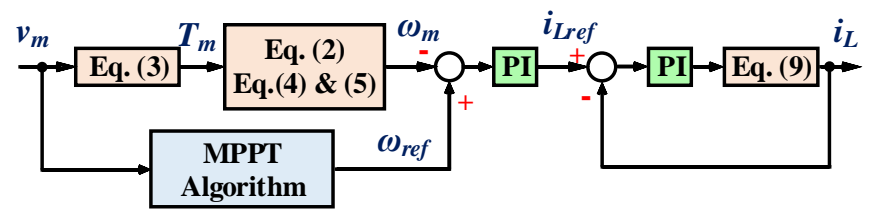

Fig. 2 Block diagram of speed control of PMSG connected to a wind/Tidal turbine

The mechanical output power of a wind turbine $P_{W m}$ can be estimated by (1)

$$
\begin{aligned}
& { }_{\text {where }} P_{W m}=0.5 \rho^{w} A^{w} C_{p}^{w}\left(\lambda^{w}, \beta^{w}\right) v_{w}^{3} \\
& \text { where } \\
& \qquad C_{p}^{w}=0.5176\left(\frac{116}{\lambda_{i}}-0.4 \beta^{w}-5\right) \exp { }^{\frac{-21}{\lambda_{i}}}+0.0068 \lambda^{w} \\
& \lambda_{i}=1 /\left[\frac{1}{\lambda^{w}+0.08 \beta^{w}}-\frac{0.035}{\beta^{w 3}+1}\right]
\end{aligned}
$$

Where $\rho^{w}, A^{w}, C_{p}^{w}, \beta^{w}, v_{w}$ are the air density, rotor swept area, power coefficient, pitch angle and wind speed, respectively. $\lambda^{w}$ is the tip speed ratio $\left(\lambda^{w}=R^{w} \omega_{m}^{w} / v_{w}\right)$ where $R^{w}$ is the rotor radius.
The mechanical model of the wind turbine considering single mass modelling is

$$
T_{m}^{w}=J_{m}^{w} \frac{d \omega_{m}^{w}}{d t}+B_{m}^{w} \omega_{m}^{w}+T_{e}^{w}
$$

Where $T_{m}^{w}$ and $T_{e}^{w}$ are the mechanical and the electromagnetic torques (N.m). $J_{m}^{w}$ and $B_{m}^{w}$ are the shaft inertia $\left(\mathrm{kg} \cdot \mathrm{m}^{2}\right)$ and viscous friction (N.m.s). $\omega_{m}^{w}$ is the rotor mechanical speed ( $\left.\mathrm{rad} / \mathrm{s}\right)$ where $\left(\omega_{r}^{w}=\omega_{m}^{w} P_{p}^{w}\right) . P_{p}^{w}$ is the number of pole pairs.

The relation between the mechanical output power of the turbine in (1) and the mechanical model in (2) is built by inserting $P_{W m}=T_{m}^{w} \omega_{m}^{w}=T_{m}^{w}\left(\frac{\lambda^{w} v_{w}}{R^{w}}\right)$ into (1). Then the mechanical torque can be expressed as a function of wind speed as follow

$$
T_{m}^{w}=\left(0.5 \rho^{w} A^{w} C_{p}^{w}\left(\lambda^{w}, \beta^{w}\right) v_{w}^{2} R^{w}\right) / \lambda^{w}
$$

Study [12] presented a detailed mathematical derivation for a PMSG model. Stator voltage of PMSG in a $d q$ frame is

$$
\begin{gathered}
v_{d s}^{w}=R_{s}^{w} i_{d s}^{w}-\omega_{r}^{w} L_{q s}^{w} i_{q s}^{w}+L_{d s}^{w}\left(d i_{d s}^{w} / d t\right) \\
v_{q s}^{w}=\omega_{r}^{w} L_{d s}^{w} i_{d s}^{w}+R_{s}^{w} i_{q s}^{w}+L_{q s}^{w}\left(d i_{q s}^{w} / d t\right)+\omega_{r}^{w} \psi_{r}^{w}
\end{gathered}
$$

Where $v_{d s}^{w}, v_{q s}^{w}$ are the stator voltages $(\mathrm{V}), i_{d s}^{w}, i_{q s}^{w}$ are the stator currents of PMSG in $d q$ frame (A). $R_{s}^{w}$ is the stator winding resistance $(\Omega) . \psi_{r}^{w}$ is the maximum flux linkage created by the permanent magnets $(\mathrm{Wb}) . \omega_{r}^{w}$ is the rotor electrical speed $(\mathrm{rad} / \mathrm{s})$. The generator electromagnetic torque equals

$$
T_{e}^{w}=\left(3 P_{p} / 2\right)\left[\psi_{r}^{w} i_{q s}^{w}+\left(L_{d s}^{w}-L_{q s}^{w}\right) i_{q s}^{w} i_{d s}^{w}\right]
$$

The large signal model of a DC/DC boost converter can be represented, in general, as follow

$$
\begin{gathered}
L\left(d i_{l} / d t\right)=d(t) v_{g}(t)+[1-d(t)]\left\{v_{g}(t)-v(t)\right\} \\
C\left(d v_{c} / d t\right)=[1-d(t)] i_{l}(t)-v(t) / R_{L}
\end{gathered}
$$

where $L$ and $C$ are the boost converter inductance and capacitance, respectively. $v_{g}(t)$ and $v(t)$ are the boost converter input and output voltages, respectively. $d(t)$ is the duty cycle and $R_{L}$ is the load resistance. $i_{l}$ is the inductor current while $v_{c}$ is the capacitor voltage. It is worth mention that the boost converter parameters $\left(L,, v_{g}, v, d\right.$ and $\left.i_{l}\right)$ will take different symbols for various boost converters used with wind, tidal, solar and battery systems.

Equations (1) to (6) represents a nonlinear large signal model of wind turbine, PMSG and DC/DC boost converter. Applying linear control techniques such as PI requires a linear system. So this large signal model can be linearized using Taylor expansion to obtain a linearized small signal model. It is worth mention that all variables in small signal model will be denoted by ( $\widehat{)}$ and initial values are denoted by $\left({ }_{0}\right)$. Equation (3) shows that the turbine torque $T_{m}^{w}$ is a function of the wind speed $v_{w}$, turbine speed $\omega_{m}^{w}$ and the pitch angle $\beta^{w}$. Replacing $C_{p}^{w}$ in (3) with its value in (1), then taking partial derivative for (3) with respect to $\omega_{m}^{w}, v_{w}$ and $\beta^{w}$ with applying Taylor expansion, one can get the linearized small signal model of (3) as follow

$$
\widehat{T}_{m}^{w}=K_{t v}^{w} \hat{v}_{m}^{w}+K_{t \omega}^{w} \widehat{\omega}_{m}^{w}+K_{t \beta}^{w} \hat{\beta}^{w}
$$


where

$\left.\left.K_{t v}^{w}=\frac{\partial T_{m}^{w}}{\partial v_{w}}\right]_{v_{w 0^{\prime}} \omega_{m 0^{\prime}}^{w} \beta_{0}^{w}}, \quad K_{t \omega}^{w}=\frac{\partial T_{m}^{w}}{\partial \omega_{m}^{w}}\right]_{v_{w 0^{\prime}} \omega_{m 0^{\prime}}^{w} \beta_{0}^{w}}$,
$\left.K_{t \beta}^{w}=-\frac{\partial T_{m}^{W}}{\partial \beta^{w}}\right]_{v_{w 0^{\prime}} \omega_{m 0^{\prime}}^{w} \beta_{0}^{w}}$

The gains $\left(K_{t v}^{w}, K_{t \omega}^{w}\right.$ and $\left.K_{t \beta}^{w}\right)$ are varying with changing the system operating point. However, as the turbine speed cannot be changed rapidly; hence the effect due to the turbine speed variation on the turbine torque is ignored, i.e. $K_{t \omega}^{w}=0$. Also, the pitch control is not used for MPPT; hence the term $K_{t \beta}^{w} \hat{\beta}^{w}$ in (8) should be ignored [13]. By replacing $T_{m}^{w}$ in (2) with (7), the linearized small signal model of a wind turbine is given.

$$
\widehat{\omega}_{m}^{w}=\frac{K_{t v}^{w} \hat{v}_{m}^{w}-K_{t \beta}^{w} \hat{\beta}^{w}-\widehat{T}_{e}^{w}}{J_{m}^{w} s+B_{m}^{w}}
$$

Similarly, applying Taylor expansion for the nonlinear large signal model of the PMSG (4), one can get the linearized small signal as follow

$$
\begin{aligned}
& \hat{\imath}_{d s}^{w}=\left(\hat{v}_{d s}^{w}+K_{\omega d}^{w} \widehat{\omega}_{m}^{w}+K_{i q d}^{w} \hat{\imath}_{q s}^{w}\right) /\left(L_{d s}^{w} s+R_{s}^{w}\right) \\
& \hat{\imath}_{q s}^{w}=\left(\hat{v}_{q s}^{w}-K_{\omega q}^{w} \widehat{\omega}_{m}^{w}-K_{i d q}^{w} \hat{\imath}_{d s}^{w}\right) /\left(L_{q s}^{w} s+R_{s}^{w}\right)
\end{aligned}
$$

where

$K_{\omega d}^{w}=P_{p}^{w} L_{q s}^{w} i_{q s 0}^{w}, K_{\omega q}^{w}=P_{p}^{w} L_{d s}^{w} i_{d s 0}^{w}+P_{p}^{w} \psi_{r}^{w}, K_{i q d}^{w}=P_{p}^{w} L_{q s}^{w} \omega_{m 0}^{w}$ and $K_{i d q}^{w}=P_{p}^{w} L_{d s}^{w} \omega_{m 0}^{w}$.

The electromagnetic torque in (5) can be linearized using Taylor expansion as follow

where

$$
\widehat{T}_{e}^{w}=K_{\text {tiqs }}^{w} \hat{l}_{q s}^{w}+K_{\text {tids }}^{w} \hat{\imath}_{d s}^{w}
$$

$K_{\text {tiqs }}^{w}=1.5 P_{p}^{w}\left[\psi_{r}^{w}+\left(L_{d s}^{w}-L_{q s}^{w}\right) i_{d s 0}^{w}\right]$

$K_{\text {tids }}^{w}=1.5 P_{p}^{w}\left(L_{d s}^{w}-L_{q s}^{w}\right) i_{q s 0}^{w}$

As per Fig. 2, MPPT control requires manipulating the inductor current of boost converter to get the generator working at the optimal speed. This can be achieved by changing the duty cycle of the boost converter as a control input with a feedback from the inductor current of the converter as shown in Fig. 3 of the linearized small signal model of a current programmed DC/DC converter. Fig. 3 shown that the inductor current and the output voltage of the boost converter depends on the duty cycle and the input voltage as per these equations

$$
\begin{gathered}
\hat{v}_{o}(s)=G_{v_{o} d}^{w}(s) \hat{d}_{w}(s)+G_{v_{o} g}^{w}(s) \hat{v}_{g}^{w}(s) \\
\hat{\imath}_{l}^{w}(s)=G_{i_{l} d}^{w}(s) \hat{d}_{w}(s)+G_{i_{l} g}^{w}(s) \hat{v}_{g}^{w}(s)
\end{gathered}
$$

Where $\hat{v}_{o}$ is the voltage of the local DC-bus, $\hat{v}_{g}^{w}$ is the input voltage of the boost converter connected to the wind turbine, $\hat{\imath}_{l}^{w}$ and $\hat{d}_{w}$ are the inductor current and the duty cycle of the same boost converter. The transfer functions of this converter are given as follow [14]

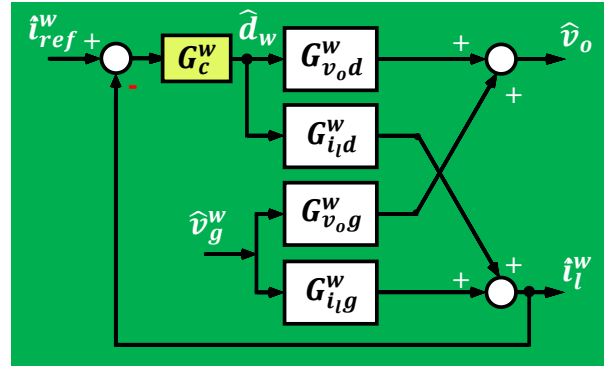

Fig. 3. A current programmed boost converter model

$$
\begin{gathered}
G_{v_{o} d}^{w}=\frac{\hat{v}_{o}(s)}{\hat{d}_{w}(s)}=G_{d o}^{w} \frac{\left(1-\frac{s}{\omega_{z}^{w}}\right)}{\operatorname{den}^{w}(s)} \\
G_{v_{o} g}^{w}=\frac{\hat{v}_{o}(s)}{\hat{v}_{g}^{w}(s)}=G_{g o}^{w} \frac{1}{\operatorname{den}^{w}(s)} \\
G_{i_{l} d}^{w}=\frac{\hat{\imath}_{l}^{w}(s)}{\hat{d}_{w}(s)}=\left(\frac{2 V_{o}}{\grave{D}_{w}{ }^{2} R_{L}^{w}}\right) \frac{\left[1+s 0.5 R_{L}^{w} C_{w}\right]}{\operatorname{den}^{w}(s)} \\
G_{i_{l} g}^{w}=\frac{\hat{\imath}_{l}^{w}(s)}{\hat{v}_{g}^{W}}=\left(\frac{1}{\grave{D}_{w}{ }^{2} R_{L}^{w}}\right) \frac{\left[1+s R_{L}^{w} C_{w}\right]}{\operatorname{den}^{w}(s)}
\end{gathered}
$$

Where $\operatorname{den}^{w}(s)=\left(1+\frac{s}{Q^{w} \omega_{o}^{w}}+\left(\frac{s}{\omega_{o}^{w}}\right)^{2}\right), G_{d o}^{w}=\frac{V_{o}}{\left(\grave{D}_{w}\right)}, \omega_{z}^{w}=\frac{\grave{D}_{w}{ }^{2} R_{L}^{w}}{L_{w}}$, $\omega_{o}^{w}=\frac{\grave{D}_{w}}{\sqrt{L_{w} C_{w}}}, Q^{w}=\grave{D}_{w} R_{L}^{w} \sqrt{\frac{C_{w}}{L_{w}}}, G_{g o}^{w}=\frac{1}{\grave{D}_{w}}$ and $\grave{D}_{w}=\left(1-D_{w}\right)$.

$V_{o}, D_{w}, L_{w}$ and $C_{w}$ are steady state values of the localbus voltage, duty cycle and the inductance and capacitance of the boost converter connected to a wind turbine, respectively.

Equations (7) to (12) represents the mathematical linearized small signal model of wind turbine, PMSG and boost converter as the block diagram of Fig. 4a shows.

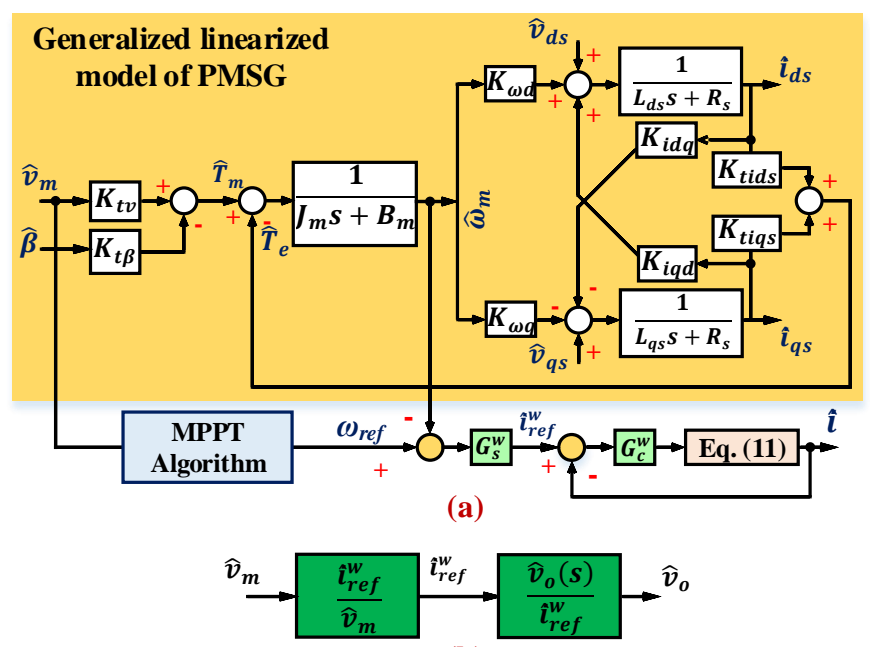

(b)

Fig. 4 (a) Small signal block diagram of wind turbine, PMSG and boost converter with speed control, (b) simplified block diagram

and

$$
G_{s}^{w}=k_{s}^{w}\left(1+\frac{1}{s} \frac{1}{T_{S}^{w}}\right)
$$

$$
G_{c}^{w}=k_{c}^{w}\left(1+\frac{1}{s} \frac{1}{T_{c}^{w}}\right)
$$


Fig. 4a illustrates two PI controllers with transfer functions $G_{s}^{w}$ and $G_{c}^{w}$ for speed and current regulation, respectively. $k_{s}^{w}$ and $k_{c}^{w}$ are the proportional gains while $T_{s}^{w}$ and $T_{c}^{w}$ are the integral gains of the speed and current controllers, respectively. The first PI controller generates the reference current for the second controller. In Fig. 4a, it is required to obtain the closed loop transfer function between the inductor current $\hat{\imath}_{l}^{w}$ and the reference current $\hat{\imath}_{\text {ref }}^{w}$ for stability analysis purposes. The reference current-to-inductor current transfer function can be derived using the second line of (11) by substituting $\hat{d}_{w}$ with $\left[G_{c}^{w}\left(\hat{\imath}_{r e f}^{w}-\hat{\imath}_{l}^{w}\right)\right]$ and applying superposition theorem, i.e. putting $\hat{v}_{g}^{w}=0$. One can get the required transfer function as follow

$$
\frac{\hat{i}_{l}^{w}}{\hat{i}_{r e f}^{w}}=\frac{G_{i_{l} d}^{w} G_{c}^{w}}{1+G_{i_{l} d}^{w} G_{c}^{w}}
$$

The stability of the current closed-loop of Fig. 3 depends on the roots of the denominator of (14) which is the characteristic equation $\left(1+G_{i l d}^{w} G_{c}^{w}=0\right)$. The coefficients of this equation are all positive which means that all roots are on the left half-plane of s-plane. i.e. the closed-loop current transfer function of (14) is stable.

To analyse the stability of the DC-bus voltage (DC voltage of the turbine) with varying the wind speed, it is required to derive the transfer function between the voltage of the local DC-bus and the wind speed as per the simplified block diagram of Fig. $4 \mathrm{~b}$. The required transfer function comprises two transfer functions which are $\frac{\hat{i}_{r e f}^{w}}{\hat{v}_{m}}$ and $\frac{\hat{v}_{o}(s)}{\hat{i}_{r e f}^{w}}$. The transfer function from the wind speed to the reference current transfer function can be derived from the block diagram of Fig. 4 a which yields

$$
\begin{gathered}
\hat{\imath}_{r e f}^{w}=G_{s}^{w}\left(\widehat{\omega}_{r e f}^{w}-\widehat{\omega}_{m}^{w}\right) \\
\frac{\hat{\imath}_{r e f}^{w}}{\hat{v}_{m}}=G_{s}^{w}\left(f\left(P_{W m}\right)-\frac{Q_{c}^{w} K_{t v}^{w}}{1+Q_{c}^{w} Z^{w}}\right)
\end{gathered}
$$

Where

$$
\begin{aligned}
& Q_{c}^{w}=\frac{1}{\left(J_{m}^{w} S+B_{m}^{w}\right)}, Z^{w}=K_{t i q s}^{w} Y^{w}+K_{t i d s}^{w} X^{w} \\
& f\left(P_{W m}\right)=-0.5551 P_{w m}{ }^{2}+1.183 P_{w m}+0.425 \\
& X^{w}=\frac{a_{1}^{w} s+a_{2}^{w}}{b_{1}^{w} S^{2}+b_{2}^{w} s+b_{3}^{w}} \quad, \quad Y^{w}=\frac{-\left(a_{3}^{w} s+a_{4}^{w}\right)}{b_{1}^{w} S^{2}+b_{2}^{w} s+b_{3}^{w}} \\
& a_{1}^{w}=L_{s s}^{w} K_{\omega d}^{w}, a_{2}^{w}=R_{s}^{w} K_{\omega d}^{w}-K_{i d d}^{w} K_{\omega q}^{w}, a_{3}^{w}=L_{d s}^{w} K_{\omega q}^{w}, a_{4}^{w}=R_{s}^{w} K_{\omega q}^{w}+ \\
& K_{i d q}^{w} K_{\omega d}^{w}, b_{1}^{w}=L_{q s}^{w} L_{d s}^{w}, b_{2}^{w}=\left(L_{q s}^{w}+L_{d s}^{w}\right) R_{s}^{w}, b_{3}^{w}=R_{s}^{w}+K_{i d q}^{w} K_{i q d}^{w} .
\end{aligned}
$$

The transfer function between the reference current $\hat{t}_{r e f}^{w}$ and the local bus voltage $\hat{v}_{o}$ can be obtained using Fig. 3 and (11). From Fig. 3 , one can obtain $d_{w}=G_{c}^{w}\left(\hat{\imath}_{r e f}^{w}-\hat{\imath}_{l}^{w}\right)$. From this equation, put the value of $\hat{l}_{l}^{w}$ into the second line of (11) afterwards solve for $d_{w}$ then put it in the first line of (11). One can get the DCbus voltage as a function of the reference current and the input voltage as follow

$$
\hat{v}_{o}=\frac{G_{v_{o} d}^{w} G_{c}^{w}}{1+G_{c}^{w} G_{i_{l} d}^{w}} \hat{l}_{r e f}^{w}+\frac{\operatorname{num}^{w}(s)}{1+G_{c}^{w} G_{i_{l} d}^{W}} \hat{v}_{g}^{w}
$$

where $\operatorname{num}^{w}(s)=G_{v_{o} g}^{w}\left(1+G_{c}^{w} G_{i_{l} d}^{w}\right)-G_{c}^{w} G_{i_{l} g}^{w}$

By substituting $\hat{i}_{r e f}^{w}$ into (16) with its value from (15) one can obtain the overall transfer function of a wind turbine with PMSG and a boost converter as follow

$$
\begin{aligned}
\hat{v}_{o}(s)=\left(f\left(P_{W m}\right)\right. & \left.-\frac{Q_{c}^{w} K_{t v}^{w}}{1+Q_{c}^{w} Z^{w}}\right)\left(\frac{G_{s}^{w} G_{v_{o} d}^{w} G_{c}^{w}}{1+G_{c}^{w} G_{i_{l} d}^{w}}\right) \hat{v}_{w} \\
& +\frac{n u m^{w}(s)}{1+G_{c}^{w} G_{i_{l} d}^{w}} \hat{v}_{g}^{w}
\end{aligned}
$$

As mentioned earlier, the tidal turbine has a similar dynamic behaviour as the wind turbine as per (1) with two differences. Instead of the air density, water density is considered for tidal case and water current speed is applied instead of wind speed. Also, the same configuration of wind turbine is considered for tidal turbine, so the overall transferfunction of the wind turbine hold for the tidal turbine which can be copied from (17) considering the mentioned differences between the wind and the tidal turbines and the parameters of the turbine and the PMSG of each case.

$$
\begin{aligned}
\hat{v}_{o}(s)=\left(f\left(P_{T m}\right)\right. & \left.-\frac{Q_{c}^{T} K_{t v}^{T}}{1+Q_{c}^{T} Z^{T}}\right)\left(\frac{G_{s}^{T} G_{v_{o} d}^{T} G_{c}^{T}}{1+G_{c}^{T} G_{i_{l}}^{T}}\right) \hat{v}_{T} \\
& +\frac{n u m^{T}(s)}{1+G_{c}^{T} G_{i_{l} d}^{T}} \hat{v}_{g}^{T}
\end{aligned}
$$

where

$$
\left.Q_{c}^{T}=\frac{1}{\left(J_{m}^{T} s+B_{m}^{T}-K_{t \omega}^{T}\right)}, \quad K_{t v}^{T}=\frac{\partial T_{m}^{T}}{\partial v_{T}}\right]_{v_{T 0^{\prime}} \omega_{m 0^{\prime}}^{T} \beta_{0}^{T}}
$$

$f\left(P_{T m}\right)=-0.5551 P_{T m}^{2}+1.183 P_{T m}+0.425$,

$\left.Z^{T}=K_{\text {tiqs }}^{T} Y^{T}+K_{t i d s}^{T} X^{T} \quad, \quad K_{t \omega}^{w}=\frac{\partial T_{m}^{w}}{\partial \omega_{m}^{W}}\right]_{v_{w 0}{ }^{\prime} \omega_{m 0}^{w} \beta_{0}^{w}}$

$X^{T}=\frac{a_{1}^{T} s+a_{2}^{T}}{b_{1}^{T} s^{2}+b_{2}^{T} s+b_{3}^{T}} \quad, \quad Y^{T}=\frac{-\left(a_{3}^{T} s+a_{4}^{T}\right)}{b_{1}^{T} s^{2}+b_{2}^{T} s+b_{3}^{T}}$

$a_{1}^{T}=L_{q s}^{T} K_{\omega d}^{T}, a_{2}^{T}=R_{s}^{T} K_{\omega d}^{T}-K_{i q d}^{T} K_{\omega q}^{T}, a_{3}^{T}=L_{d s}^{T} K_{\omega q}^{T}, a_{4}^{T}=R_{s}^{T} K_{\omega q}^{T}+$ $K_{i d q}^{T} K_{\omega d}^{T}, b_{1}^{T}=L_{q s}^{T} L_{d s}^{T}, b_{2}^{T}=\left(L_{q s}^{T}+L_{d s}^{T}\right) R_{s}^{T}, b_{3}^{T}=R_{s}^{T^{2}}+K_{i d q}^{T} K_{i q d}^{T}$.

$G_{s}^{T}=k_{s}^{T}\left(1+\frac{1}{s} \frac{1}{T_{s}^{T}}\right), \quad G_{c}^{T}=k_{c}^{T}\left(1+\frac{1}{s} \frac{1}{T_{c}^{T}}\right)$

$G_{v_{o} d}^{T}=\frac{\hat{v}_{o}(s)}{\hat{d}_{T}(s)}=G_{d o}^{T} \frac{\left(1-\frac{s}{\omega_{z}^{T}}\right)}{\operatorname{den}^{T}(s)}, \quad G_{i_{l} d}^{T}=\left(\frac{2 V_{o}}{\grave{D}_{T}{ }^{2} R_{L}^{T}}\right) \frac{\left[1+s 0.5 R_{L}^{T} C_{T}\right]}{\operatorname{den}^{T}(s)}$

$G_{v_{o} g}^{T}=\frac{\hat{v}_{o}(s)}{\hat{v}_{g}^{T}(s)}=G_{g o}^{T} \frac{1}{\operatorname{den}^{T}(s)}, \quad G_{i_{l} g}^{T}=\frac{\hat{\imath}_{l}^{T}(s)}{\hat{v}_{g}^{T}}=\left(\frac{1}{\grave{D}_{T}{ }^{2} R_{L}^{T}}\right) \frac{\left[1+s R_{L}^{T} C_{T}\right]}{\operatorname{den}^{T}(s)}$

$\operatorname{den}^{T}(s)=\left(1+\frac{s}{Q^{T} \omega_{o}^{T}}+\left(\frac{s}{\omega_{o}^{T}}\right)^{2}\right), G_{d o}^{T}=\frac{V_{o}}{\left(\grave{D}_{T}\right)}, \omega_{z}^{T}=\frac{D_{T}^{2} R_{L}^{T}}{L_{T}}, \omega_{o}^{T}=\frac{D_{T}}{\sqrt{L_{T} C_{T}}}, Q^{T}=$ $\grave{D}_{T} R_{L}^{T} \sqrt{\frac{C_{T}}{L_{T}}}, G_{g o}^{T}=\frac{1}{\grave{D}_{T}}, \grave{D}_{T}=\left(1-D_{T}\right)$.

$\operatorname{num}^{T}(s)=G_{v_{o} g}^{T}\left(1+G_{c}^{T} G_{i_{l} d}^{T}\right)-G_{c}^{T} G_{i_{l} g}^{T}$

$V_{o}, D_{T}, L_{T}$ and $C_{T}$ are steady state values of the local bus voltage, duty cycle and the inductance and capacitance of the boost converter connected to a tidal turbine, respectively. $P_{T m}$ is the mechanical output power of a tidal turbine. $f\left(P_{T m}\right)$ is the MPPT algorithm which gives the optimal per unit rotor speed as a reference at various mechanical input powers. $\hat{v}_{g}^{T}$ is the input voltage variations of the boost converter connected to a tidal turbine. $\hat{v}_{T}$ is water current speed as sociated to a tidal turbine. 


\section{SYSTEM ST ABILITY ANALYSIS}

Equation (17) and (18) shows that the stability of the output voltage of the tidal/wind turbine depends on the characteristic equations (i.e. the denominators of the transfer functions of those equations which are

$$
\begin{gathered}
\left(1+Q_{c}^{w} Z^{w}\right)\left(1+G_{c}^{w} G_{i_{l} d}^{w}\right)=0 \\
1+G_{c}^{w} G_{i_{l} d}^{w}=0 \\
\left(1+Q_{c}^{T} Z^{T}\right)\left(1+G_{c}^{T} G_{i_{l} d}^{T}\right)=0 \\
1+G_{c}^{T} G_{i_{l} d}^{T}=0
\end{gathered}
$$

Routh-Hurwitz stability criterion states for the closed-loop transfer function of a system to be stable, the characteristic equation of that system must have all zeros on the left halfplane. To ensure that the characteristic equations of (19) have all zeros on the left half-plane, one should ensure their numerators have only positive coefficients. For the term $\left(1+G_{c}^{W} G_{i_{l} d}^{W}\right)$, it shows positive coefficients as the transfer functions $G_{c}^{w}$ and $G_{i l d}^{w}$ have only positive coefficients. Similarly, this analys is is valid for the characteristic equations in (19) that having the similar term. To examine the term $\left(1+Q_{c}^{w} Z^{w}\right)$, it is expanded to show its coefficients which yields

where

$$
1+Q_{c}^{w} Z^{w}=g_{3} s^{3}+g_{2} s^{2}+g_{1} s+g_{0}=0
$$

$g_{3}=J_{m}^{w} L_{q s}^{w} L_{d s}^{w}$

$g_{2}=J_{m}^{w}\left(L_{q s}^{w}+L_{d s}^{w}\right) R_{s}^{w}+B_{m}^{w} L_{q s}^{w} L_{d s}^{w}$

$g_{1}=J_{m}^{w}\left[R_{s}^{w 2}+\left(P_{p}^{w} L_{d s}^{w} \omega_{m 0}^{w}\right)\left(P_{p}^{w} L_{q s}^{w} \omega_{m 0}^{w}\right)\right]+B_{m}^{w}\left(L_{q s}^{w}+L_{d s}^{w}\right) R_{s}^{w}$

$+L_{q s}^{w}\left(P_{p}^{w} L_{q s}^{w} i_{q s 0}^{w}\right)\left(1.5 P_{p}^{w}\left(L_{d s}^{w}-L_{q s}^{w}\right) i_{q s 0}^{w}\right)$

$-L_{d s}^{w}\left(P_{p}^{w} L_{d s}^{w} i_{d s 0}^{w}\right)\left(1.5 P_{p}^{w}\left[\psi_{r}^{w}+\left(L_{d s}^{w}-L_{q s}^{w}\right) i_{d s 0}^{w}\right]\right)$

$g_{0}=B_{m}^{w}\left[R_{s}^{w^{2}}+\left(P_{p}^{w} L_{d s}^{w} \omega_{m 0}^{w}\right)\left(P_{p}^{w} L_{q s}^{w} \omega_{m 0}^{w}\right)\right]+\left[R_{s}^{w} P_{p}^{w} L_{q s}^{w} i_{q s 0}^{w}-\right.$

$\left.\left(P_{p}^{w} L_{q s}^{w} \omega_{m 0}^{w}\right)\left(P_{p}^{w} L_{d s}^{w} i_{d s 0}^{w}\right)\right]\left(1.5 P_{p}^{w}\left(L_{d s}^{w}-L_{q s}^{w}\right) i_{q s 0}^{w}\right)-\left[R_{s}^{w} P_{p}^{w} L_{d s}^{w} i_{d s 0}^{w}+\right.$

$\left.\left(P_{p}^{w} L_{d s}^{w} \omega_{m 0}^{w}\right)\left(P_{p}^{w} L_{q s}^{w} i_{q s 0}^{w}\right)\right]\left(1.5 P_{p}^{w}\left[\psi_{r}^{w}+\left(L_{d s}^{w}-L_{q s}^{w}\right) i_{d s 0}^{w}\right]\right)$

The steady state currents $i_{q s 0}^{w}$ and $i_{d s 0}^{w}$ are negative for PMSG. The coefficients $g_{3}$ and $g_{2}$ are positive values for both SPMSG and IPMSG. First, considering SPMSG (i.e. $i_{d s 0}^{w}=0$ and $\left(L_{d s}^{w}-L_{q s}^{w}\right)=0$ ) this means that $g_{1}$ is positive as the third and fourth terms of $g_{1}$ will be zero. The Coefficient $g_{0}$ has a positive sign as the third term goes to zero. Secondly, if IPMSG considered (i.e. $L_{d s}^{w} \neq L_{q s}^{w}$ ), then the third term of $g_{1}$ will tum to negative due to the negative sign of $i_{q s 0}^{w}$ and the fourth term will turn to positive. Similarly the third term of $g_{0}$ will turn to positive while the sign of the second termof this coefficient will be positive if $\left(P_{p}^{w} \omega_{m 0}^{w} L_{d s}^{w} i_{d s 0}^{w}>R_{s}^{w} i_{q s 0}^{w}\right)$. The same analysis is applied to the characteristic equation of the tidal turbine in the third line of (19).

\section{SIMUlation}

This section evaluates the performance of the proposed controller for extracting the maximum power from a variable speed wind/tidal turbines using a boost converter. It is worth mention that the pitch controller and the DC output voltage regulation are out of the scope of this paper which focus on analyzing the dynamic response of the tidal/wind turbine for extracting maximum power at and below the rated turbine power.

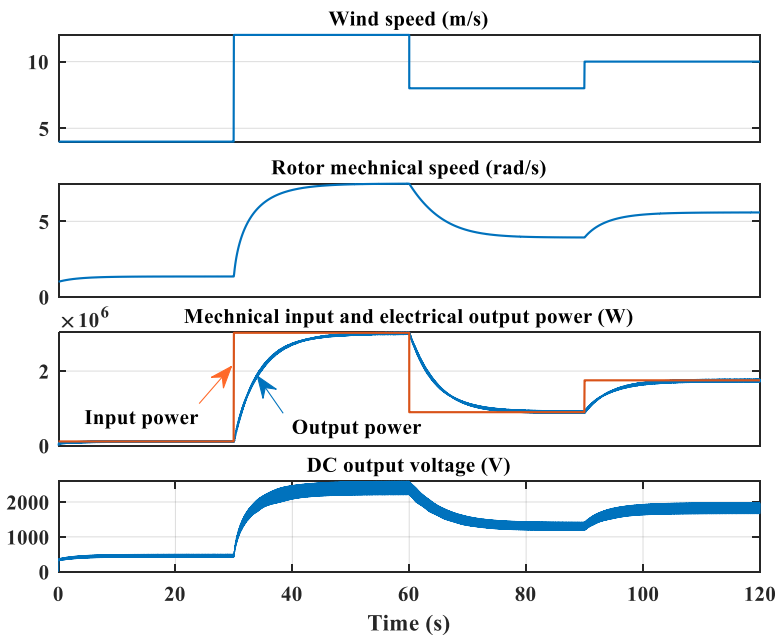

Fig. 5. Wind turbine response at various wind speed and shows generator rotor speed, mechanical input and electrical output power and the output DC voltage
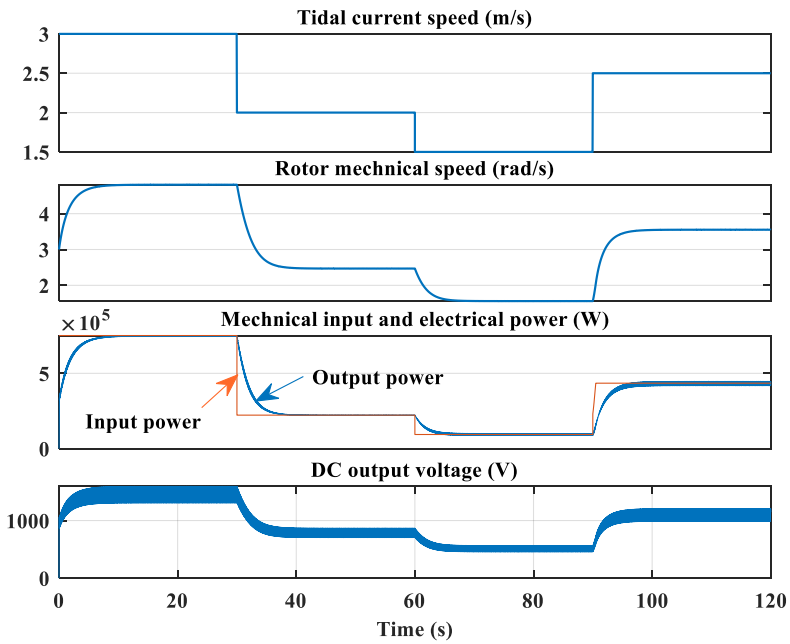

Fig. 6 Tidal turbine response at various current speed and shows gener ator rotor speed, mechanical input and electrical output power and the output DC voltage

Fig. 5 shows the wind turbine response at various wind speed. The figures confirm the stability analysis provided in the previous section. The wind turbine is controlled in a stable way for extracting the maximum power using the boost converter. For example, at $30 \mathrm{~s}$ the wind speed changed from 4 to $12 \mathrm{~m} / \mathrm{s}$ which result in increasing the output power from $112 \mathrm{~kW}$ to 3 $\mathrm{MW}$ and this increases the rotor speed to around $1.5 \mathrm{rad} / \mathrm{s}$. Fig. 5 shows that the turbine DC output voltage is stable at various wind speed, although this voltage is not regulated as this out of the scope of this study as mentioned earlier, and this conforms the stability analysis built in the previous section based on equation (17). 
Fig. 6 shows the dynamic response for $750 \mathrm{~kW}$ a tidal turbine. The turbine parameters are given in table I in the appendix. The figure shows that the turbine DC output voltage is stable at various tidal current speeds which confirm the stability analys is introduced in the previous section based on (18).

\section{CONCLUSION}

The paperpresented a modelling and stability analysis for a DC wind/tidal turbines based PMSG. The common configuration, in literature, for a DC wind turbine is a diode rectifier with boost or buck converter for extracting the maximum power. Two cascaded loops PI controller is used: the outer loop used for tracking the optimal turbine speed which gives the reference current to the inner loop. The inner loop used to help the inductor current of the boost converter tracking the reference current provided by the outer loop. A generalized small-signal model is derived for a wind/tidal turbines based PMSG and boost converter. Stability analys is is held for the output voltage of the turbine at various wind/tidal current speeds which shows the system is stable at all speeds. Simulation setup is created using Matlab/Simulink for a wind and tidal turbines which confirm the stability of the turbines with the DC boost converter at various speeds.

\section{REFERENCES}

[1] W. M. Nassar, O. Anaya-Lara, K. H. Ahmed, D. CamposGaona, and M. Elgenedy, "Assessment of multi-use offshore platforms: structure classification and design challenges," Sustainability, vol. 12, no. 5, p. 1860, 2020.

[2] Z. Zhao, J. Hu, and H. Chen, "Bus Voltage Control Strategy for Low Voltage DC Microgrid Based on AC Power Grid and Battery," in 2017 IEEE International Conference on Energy Internet (ICEI), 17-21 April 2017 2017, pp. 349-354, doi: 10.1109/ICEI.2017.68.

[3] D. Zammit, C. S. Staines, A. Micallef, and M. Apap, "MPPT with current control for a PMSG small wind turbine in a grid-connected DC microgrid," in Research and innovation on wind energy on exploitation in urban environment colloquium, 2017: Springer, pp. 205-219.

[4] T. Dragičević, J. M. Guerrero, J. C. Vasquez, and D. Škrlec, "Supervisory Control of an Adaptive-Droop Regulated DC Microgrid With Battery Management Capability," IEEE Transactions on Power Electronics, vol. 29, no. 2, pp. 695-706, 2014, doi: 10.1109/TPEL.2013.2257857.

[5] D. Wu, F. Tang, T. Dragicevic, J. M. Guerrero, and J. C. Vasquez, "Coordinated Control Based on Bus-Signaling and Virtual Inertia for Islanded DC Microgrids," IEEE Transactions on Smart Grid, vol. 6, no. 6, pp. 2627-2638, 2015, doi: 10.1109/TSG.2014.2387357.

[6] D. Chen and L. Xu, "Autonomous DC Voltage Control of a DC Microgrid With Multiple Slack Terminals," IEEE Transactions on Power Systems, vol. 27, no. 4, pp. 18971905, 2012, doi: 10.1109/TPWRS.2012.2189441.

[7] N. L. Diaz, T. Dragičević, J. C. Vasquez, and J. M. Guerrero, "Intelligent Distributed Generation and Storage Units for DC Microgrids-A New Concept on Cooperative Control Without Communications Beyond
Droop Control," IEEE Transactions on Smart Grid, vol. 5, no. 5, pp. 2476-2485, 2014, doi: 10.1109/TSG.2014.2341740.

[8] W. Wu et al., "A Virtual Inertia Control Strategy for DC Microgrids Analogized With Virtual Synchronous Machines," IEEE Transactions on Industrial Electronics, vol. 64, no. 7, pp. 6005-6016, 2017, doi: 10.1109/TIE. 2016.2645898.

[9] Z. Yi, X. Zhao, D. Shi, J. Duan, Y. Xiang, and Z. Wang, "Accurate Power Sharing and Synthetic Inertia Control for DC Building Microgrids With Guaranteed Performance," IEEE Access, vol. 7, pp. 63698-63708, 2019, doi: 10.1109/ACCESS.2019.2915046.

[10] M. K. Senapati, C. Pradhan, S. R. Samantaray, and P. K. Nayak, "Improved power management control strategy for renewable energy-based DC micro-grid with energy storage integration," IET Generation, Transmission \& Distribution, vol. 13, no. 6, pp. 838-849, 2019, doi: 10.1049/iet-gtd.2018.5019.

[11] M. Davari and Y. A. I. Mohamed, "Robust DC-Link Voltage Control of a Full-Scale PMSG Wind Turbine for Effective Integration in DC Grids," IEEE Transactions on Power Electronics, vol. 32, no. 5, pp. 4021-4035, 2017 , doi: 10.1109/TPEL. 2016.2586119.

[12] V. Yaramasu and B. Wu, Model Predictive Control of Wind Energy Conversion Systems. John Wiley \& Sons, 2016.

[13] M. Nasiri, J. Milimonfared, and S. H. Fathi, "Modeling, analysis and comparison of TSR and OTC methods for MPPT and power smoothing in permanent magnet synchronous generator-based wind turbines," Energy Conversion and Management, vol. 86, pp. 892-900, 2014/10/01/ 2014, doi: https://doi.org/10.1016/j.enconman.2014.06.055.

[14] R. w. Erickson and D. Maksimovic, Fundamental of Power Electronics. Colorado: Springer, 2001.

\section{APPENDIX}

\begin{tabular}{|c|c|c|}
\hline \multicolumn{3}{|c|}{ SYSTEM PARAMETERS LIST } \\
\hline Description & Wind Turbine & Tidal Turbine \\
\hline \multicolumn{3}{|l|}{ Turbine parameters } \\
\hline Rayed power (kW) & 3000 & 750 \\
\hline Rotor radius (m) & 51 & 7.025 \\
\hline Air density/ Water density $\left(\mathrm{kg} / \mathrm{m}^{2}\right)$ & 1.225 & 1025 \\
\hline Rated wind/current speed $(\mathrm{m} / \mathrm{s})$ & 12 & 3 \\
\hline \multicolumn{3}{|l|}{ PMSG parameters } \\
\hline Generator pole pairs & 26 & 26 \\
\hline Shaft moment of inertia (kg.m2) & $446 \mathrm{e} 3$ & $117 \mathrm{e} 3$ \\
\hline Viscous friction (N.m.s) & 0.001189 & 0.001189 \\
\hline Stator phase resistance $\mathrm{Rs}(\mathrm{m} \Omega)$ & 1.63 & 6.52 \\
\hline Direct stator inductance $(\mathrm{mH})$ & 0.94 & 3.74 \\
\hline Quadrature stator inductance $(\mathrm{mH})$ & 1.47 & 5.88 \\
\hline Flux linkage (V.s) & 8.295 & 8.295 \\
\hline \multicolumn{3}{|l|}{ Boost converter parameters } \\
\hline Input boost inductor, $L(\mathrm{mH})$ & 1.7 & 1.2 \\
\hline Output boost capacitor, $C(\mu \mathrm{F})$ & 24.9 & 3 \\
\hline Load impedance, $Z_{L}(\Omega)$ & 2 & 3 \\
\hline Switching frequency $(\mathrm{kHz})$ & 50 & 50 \\
\hline \multicolumn{3}{|l|}{ System parameters } \\
\hline Speed controller proportional gain, $k_{s p}$ & 800 & 800 \\
\hline Speed controller integral gain, $k_{s i}$ & 0.03 & 0.03 \\
\hline Current controller proportional gain, $k_{c p}$ & 500 & 500 \\
\hline Current controller integral gain, $k_{c i}$ & 50 & 50 \\
\hline
\end{tabular}

